\title{
La Ballade, histoire et avatars d'une forme poétique, dir. B. BUFFARD-MORET et M. DEMAULES
}

\section{Elisabetta Barale}

\section{(2) OpenEdition}

\section{Journals}

\section{Édition électronique}

URL : https://journals.openedition.org/studifrancesi/44744

DOI : $10.4000 /$ studifrancesi. 44744

ISSN : 2427-5856

Éditeur

Rosenberg \& Sellier

\section{Édition imprimée}

Date de publication : 1 août 2021

Pagination : 352-353

ISSN : 0039-2944

\section{Référence électronique}

Elisabetta Barale, "La Ballade, histoire et avatars d'une forme poétique, dir. B. BUFFARD-MORET et M.

DEMAULES », Studi Francesi [En ligne], 194 (LXV | II) | 2021, mis en ligne le 06 septembre 2021, consulté le 15 octobre 2022. URL : http://journals.openedition.org/studifrancesi/44744 ; DOI : https://doi.org/ 10.4000/studifrancesi.44744

Ce document a été généré automatiquement le 15 octobre 2022.

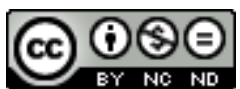

Creative Commons - Attribution - Pas d'Utilisation Commerciale - Pas de Modification 4.0 International - CC BY-NC-ND 4.0

https://creativecommons.org/licenses/by-nc-nd/4.0/ 


\title{
La Ballade, histoire et avatars d'une forme poétique, dir. B. BUFFARD-MORET et M. DEMAULES
}

\author{
Elisabetta Barale
}

\section{RÉFÉRENCE}

La Ballade, histoire et avatars d'une forme poétique, dir. B. BUFFARD-MORET et M. DEMAULES, Paris, Champion, 2020, «Colloques, congrès et conférences sur le Moyen Âge» 27, 365 pp.

1 Issu d'un Colloque qui s'est déroulé à l'Université d'Artois du 30 novembre au 2 décembre 2016, ce volume réunit dix-huit études visant à élaborer une définition plus précise du genre poétique de la ballade et à en retracer l'histoire depuis son origine jusqu'à nos jours. Nous rendons compte ici des six premières contributions portant sur la littérature des $\mathrm{XIV}^{\mathrm{e}}$ et $\mathrm{XV}^{\mathrm{e}}$ siècles.

2 Sylvie LEFÈVRE s'interroge sur le sens du mot «chanson» qui, dans les textes en langue d'oïl de la fin du Moyen Âge, se trouve souvent en lien avec le mot «ballade»; en particulier, elle se demande si ce terme n'est qu'un simple hypéronyme ou bien si, au moment où la musique s'éloigne de la poésie, il se réfère à ce qui se chante encore. Son article passe en revue les premiers exemples de chansons désignées comme ballades pour montrer ensuite l'évolution d'un genre qui devient de plus en plus savant jusqu'à la théorisation du divorce entre musique artificielle et musique naturelle par Eustache Deschamps (Le couple «chançons et balades» de retours en détours, pp. 27-37).

Yolanda PLumLey se focalise sur deux chansons de Guillaume de Machaut qui permettent d'illustrer les voies par lesquelles, dans la seconde moitié du XIV siècle, la ballade accompagnée de la musique acquiert une identité plus sophistiquée. La double ballade 34, dans laquelle Machaut entretient une relation compétitive avec Thomas Paien, et la ballade 33 invitent à réfléchir sur l'importance des jeux citationnels aussi 
bien que sur le pouvoir de propagande politique exercé par l'alliance entre mots et musique (The Fourteenth-Century Ballade at the Princely Court: Songs by Guillaume de Machaut and his Contemporaries, pp. 39-54).

4 Mireille Demaules se penche sur trois chants royaux $(327,387,388)$ et deux ballades morales $(183,1010)$ d'Eustache Deschamps qui sont des songes politiques. En effet, Deschamps réussit à miniaturiser dans un moule contraignant des récits de rêve dont l'A. met en évidence les traits saillants: la structure du songe-cadre avec un envoi sans élucidation et un refrain donnant aux textes une portée morale; les procédés de l'écriture allégorique qui rapprochent les compositions du genre de la fable et du débat; l'image idéalisée du poète qui devient une sorte de prophète auprès du roi (À propos de quelques ballades oniriques d'Eustache Deschamps, pp. 55-72).

Anne-Cécile LE RIBEUZ-KOENIG analyse les pièces lyriques insérées dans Le Roman d'Ysaÿe le Triste. Cette œuvre arthurienne recèle un véritable florilège de chansons à la mode, parmi lesquelles on identifie trois ballades et trois chansons balladées composées par Marte, la jeune fille dont Ysaÿe est amoureux. Caractérisées par une recherche formelle visant à souligner le talent de la poétesse, ces compositions évoquent l'origine musicale de la ballade et son évolution vers l'écriture poétique à travers les différentes performances de l'héroüne (Les ballades chantées et lues dans "Le Roman d'Ysaÿe le Triste", de la circonstance musicale à l'insertion poétique, pp. 73-87).

Clotilde DAUPHANT relit le roman Melyador que Jean Froissart remania au début des années 1380 avec l'insertion des poèmes de son mécène, Wenceslas de Luxemburg. Auteur et éditeur de son œuvre, Froissart respecte le corpus lyrique du prince, en citant ses poèmes en entier et en les attribuant à des chevaliers fictifs dans le but de les situer dans un monde chevaleresque perdu. D'ailleurs, Wenceslas ne se laisse pas influencer par les tendances formelles de son protégé, en développant des choix personnels: ses pièces lyriques constituent un ensemble différent de celui de Froissart (L'originalité lyrique de "Melyador": ballades de prince, ou de poète?, pp. 89-106).

7 Jean-Claude MÜHLETHALER s'intéresse à La Chasse et le Depart d'Amours, recueil poétique imprimé par Antoine Vérard, peut-être en collaboration avec Blaise d'Auriol. Dans La Séparation des amants, la transgression linguistique des premières pièces cède le pas à une réorientation courtoise dans laquelle s'inscrivent les ballades de Charles d'Orléans. En revanche, le Depart présente une variété de formes lyriques plus grande et accorde plus d'importance à la théâtralisation du discours et à l'unisonance (Questions de sens, questions de forme: variations sur la ballade dans "La Chasse et Le Depart d'Amours" (1509), pp. 107-123). 